\title{
Estimation of the compression strength and surface roughness of the as-built SLS components using weibull distribution
}

\author{
Hamaid Mahmood KHAN®, Gürkan TARAKÇI®, Mustafa Enes BULDUK®, Ebubekir KOÇ® \\ Aluminum Test Training and Research Centre, Fatih Sultan Mehmet Vaklf University, Istanbul, Turkey
}

\section{ARTICLE INFO}

\section{Article history}

Received: 11 January 2021

Accepted: 24 February 2021

\section{Key words:}

Compression testing, PA2200, selective laser sintering, surface roughness, Weibull distribution.

\begin{abstract}
Selective laser sintering (SLS) is a process of fabrication of three-dimensional structures by fusing powder particles using a guided laser source. The uncertainty in the mechanical properties of the SLS parts fabricated at the same time and with the same process parameters can affect the repeatability of the SLS process. A vast difference in the mechanical properties of the concurrently processed parts can lower the production quality of the batch. Therefore, the parameters are required to be design based on the most probable outcome of the desired properties. Weibull distribution is one such statistical-based probability distribution method to measure the likelihood of the occurrence of a value of any random variable falling within a particular range of values. Here, the Weibull distribution was used to measure the relative likelihood ( $90 \%$ probability) of the surface roughness and the compressive strength values of the SLS-built polyamide PA2200 components in the given sample space that was obtained from 20 random samples. The results show that the variance in the surface roughness (scan and built plane) and the compressive strength values were in the range of 6-7 $\mu \mathrm{m}$ and around $10 \mathrm{MPa}$, respectively. Moreover, the surface roughness of the two orthogonal planes with $90 \%$ reliability was measured at $14.81 \mu \mathrm{m}$ (scan plane) and $12.15 \mu \mathrm{m}$ (built plane). Similarly, the yield strength and the compressive strength with $90 \%$ reliability were found $25.87 \mathrm{MPa}$ and $62.64 \mathrm{MPa}$, respectively.
\end{abstract}

Cite this article as: Khan HM, Tarakçı G, Bulduk ME, Koç E. Estimation of the compression strength and surface roughness of the as-built SLS components using weibull distribution. J Adv Manuf Eng 2021;2:1:1-6.

\section{INTRODUCTION}

Selective laser sintering (SLS) is a powder-based additive manufacturing $(\mathrm{AM})$ process where a computer-guided laser source sinters the powder particles to form a three-dimensional component. Prior to scanning, a layer of powder particles is spread onto the substrate or on the top of the previously scanned layer to allow the laser to scan the predefined regions [1]. The process is then repeated on all the subsequent layers, such that a strong linkage can be formed between the layers. The SLS process is quite useful in producing complex structures with superior mechanical and microstructural properties that are otherwise difficult to create using conventional techniques due to process limitations. It is because the SLS process enables the sintering of powder particles at a target location of a few hundred mi-

\footnotetext{
${ }^{\star}$ Corresponding author.

*E-mail address: hamaid.khan@gmail.com
} 
crometers to generate a complex profile, which is difficult to create using conventional techniques [2-5].

The processing parameters of the SLS process, such as the laser-based parameters (laser power, speed, scan spacing, layer thickness, and scan patterns), material parameters (powder granulometry), and the processing conditions, play a critical role in the final mechanical properties of the SLS components. The laser-based parameters are easy to control using the attached software to the SLS machines, but the particle-size distribution and the processing conditions can still alter the overall mechanical features of the SLS components. The particle-size distribution can include the size and shape of the powder particles used and the packing density that can vary with locations. A slight variation in the powder granulometry can produce unfavorable results. Moreover, the processing conditions such as the sintering location, geometry type, and atmospheric conditions are all essential parameters of the SLS process to change the mechanical properties of the final components [6-9].

Therefore, the mechanical properties of the components fabricated with the same processing parameters can have significantly different surface roughness, density, and mechanical strength. As of now, it is improbable to control the material parameters and the processing conditions of the SLM process; thus, the changes in properties are inevitable. It is, therefore, necessary to statistically analyze a large number of samples to evaluate the variation in properties and to identify the most probable outcome for final design analysis. In this study, a Weibull distribution based on the continuous probability distribution function was used to measure the probability of the occurrence of different outcomes in an experiment. It is often useful in industrial engineering, reliability engineering, and failure analysis. The measurements such as surface roughness of the two orthogonal planes were measured along with the yield and compressive strength of all the 20 samples of the PA2200 polyamide powder using the SLS process. Later, the Weibull distribution was used on the results to obtain the reliability graph [10-12].

\section{MATERIAL AND METHODS}

The PA2200 polyamide powders were used to fabricate 20 cubical samples of size $12.5 \times 12.5 \times 25 \mathrm{~mm}^{3}$ in the EOS FORMIGA P110 3D printing machine. The selected parameters for the manufacturing of the SLS samples were 21 W laser power, $2500 \mathrm{~mm} / \mathrm{s}$ scan speed, and $0.25 \mathrm{~mm}$ scan distance with an alternate scanning strategy. All the samples were prepared at the same time. The surface roughness measurements were performed on the Mitutoyo SJ210, an ES ISO 4287 certified field-oriented portable surface roughness tester. An average of 4-6 measurements (Ra) was obtained on the scan and the built planes of the as-built samples. The hardness of the samples was measured on the Future-Tech FM310e, an ASTM E384 certified standard microhardness tester. The values obtained were very close

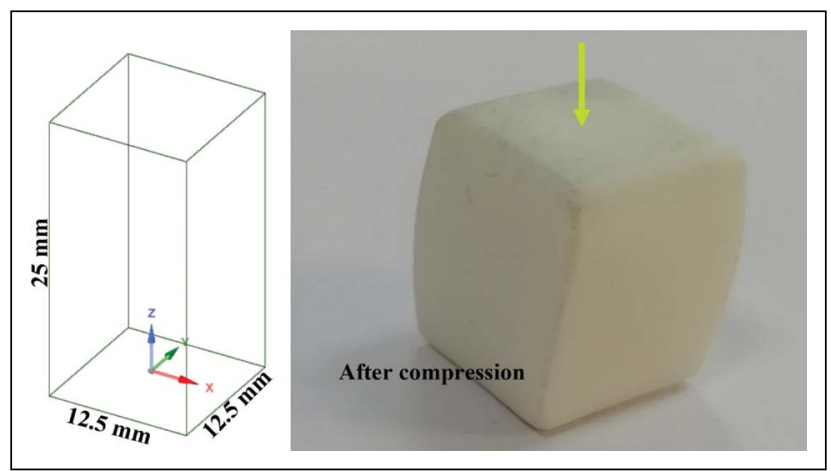

Figure 1. Schematic model of the cuboid sample and the sample after compression test.

to each other, and therefore, the hardness was not included in the Weibull analysis. The hardness of the polyamide samples was found in the range of 19-20 Hv. The compression test was performed as per standards (ASTM E 8M-04) on an Instron 5982 dual column testing system with a $100 \mathrm{kN}$ loading capacity. Figure 1 shows the schematic diagram of the sample model and the compressed sample. The downward speed of $0.5 \mathrm{~mm} / \mathrm{min}$ was used amid room conditions during the compression tests. Table 1 shows the compressive yield stress $(0.2 \%$ offset), compressive strength $(25 \%$ contraction) and the surface roughness values of the two planes (scan and built planes) of all the samples.

\section{Weibull Distribution}

The probability density function of the three-parameter Weibull random variable is given by

$$
\begin{aligned}
& f(x ; \alpha, \beta, \gamma)=1-\exp \left(-\left(\frac{x-\alpha}{\beta}\right)^{\gamma}\right), \\
& \alpha, \beta, \gamma \geq 0,
\end{aligned}
$$

In the above equation, the parameters $\alpha, \beta$, and $\gamma$ are location, shape, and scale parameters, respectively. If $\alpha=0$, the three-parameter reduces to two-parameter Weibull distribution function;

$$
\begin{aligned}
& f(x ; \beta, \gamma)=1-\exp \left(-\left(\frac{x}{\beta}\right)^{\gamma}\right), \\
& \beta, \gamma \geq 0
\end{aligned}
$$

The probability function $f(\chi ; \beta, \gamma)$ signifies that the measured variable is equal to or less than the value $\chi$. The reliability function can be defined from the probability function using the following equation;

$$
f(x ; \beta, \gamma)+r(x ; \beta, \gamma)=1
$$

Here, reliability function $r(\chi ; \beta, \gamma)$ represents the probability of the measured variable at least equal to $\chi$.

$$
\begin{aligned}
& r(x ; \beta, \gamma)=\exp \left(-\left(\frac{x}{\beta}\right)^{\gamma}\right) \\
& \beta, \gamma \geq 0,
\end{aligned}
$$


Table 1. The yield strength, compressive strength, and surface roughness, Ra, values of the scan, and the built planes of all the 20 samples

\begin{tabular}{lcccc}
\hline S. no: & $\begin{array}{c}\text { Yield strength } \\
(\mathbf{M P a})\end{array}$ & $\begin{array}{c}\text { Compressive strength } \\
(\mathbf{M P a})\end{array}$ & $\begin{array}{c}\text { Scan plane, } \mathbf{R}_{\mathbf{a}} \\
(\boldsymbol{\mu \mathbf { m } )})\end{array}$ & $\begin{array}{c}\text { Built plane, } \mathbf{R}_{\mathbf{a}} \\
(\boldsymbol{\mu m})\end{array}$ \\
\hline 1 & 31.28 & 67.61 & 16.9671 & 13.3810 \\
2 & 33.09 & 66.36 & 16.9434 & 16.5211 \\
3 & 31.16 & 66.55 & 18.2184 & 17.0847 \\
4 & 33.61 & 69.27 & 17.0053 & 13.2524 \\
5 & 32.51 & 67.85 & 18.1364 & 16.0485 \\
6 & 30.46 & 66.68 & 12.9465 & 15.5237 \\
7 & 30.17 & 65.86 & 19.8034 & 14.3133 \\
8 & 30.01 & 66.31 & 16.1642 & 13.9542 \\
9 & 27.06 & 63.32 & 15.7453 & 15.2895 \\
10 & 28.74 & 64.74 & 16.6951 & 15.9039 \\
11 & 28.15 & 64.56 & 16.0305 & 12.1907 \\
12 & 30.79 & 66.12 & 16.7345 & 13.1551 \\
13 & 26.35 & 63.28 & 16.2828 & 13.1362 \\
14 & 22.81 & 59.23 & 16.2551 & 15.8340 \\
15 & 27.91 & 63.96 & 15.2832 & 13.0490 \\
16 & 27.63 & 64.19 & 16.7475 & 11.3259 \\
17 & 28.31 & 65.12 & 15.6607 & 12.1939 \\
18 & 29.54 & 65.26 & 15.8213 & 14.0202 \\
19 & 29.97 & 66.31 & 16.2223 & 14.5913 \\
20 & 30.09 & 67.22 & 16.7112 & 15.3614 \\
\hline & & & &
\end{tabular}

In order to calculate the scale $\beta$ and shape $\gamma$ parameters of the distribution function $\mathrm{f}(\chi ; \beta, \gamma)$ A linear regression method is required. The linear regression approach is numerically used to assess the goodness of fit and to estimate the parameters of the Weibull distribution.

\section{Linear Regression Method}

Using a double logarithm, the probability function $\mathrm{f}(\chi ; \beta, \gamma)$ can be transformed into a straight-line model [13];

$$
\begin{aligned}
& f(x ; \beta, \gamma)=1-\exp \left(-\left(\frac{x}{\beta}\right)^{\gamma}\right) \\
& \ln (1-f(x ; \beta, \gamma))=\left(\frac{x}{\beta}\right)^{\gamma} \\
& \ln \left[\ln \left(\frac{1}{1-f(x ; \beta, \gamma)}\right)\right]=\gamma \ln (x)-\gamma \ln (\beta),
\end{aligned}
$$

Equation 6 is of a straight line form, $\mathrm{Y}=\mathrm{mX}+\mathrm{C}$, such that

$$
\begin{aligned}
& \mathrm{Y}=\ln \left[\ln \left(\frac{1}{1-f(x ; \beta, \gamma)}\right)\right] \\
& \mathrm{X}=\ln (x) \\
& \mathrm{m}=\gamma \\
& \mathrm{C}=-\gamma \ln (\beta)
\end{aligned}
$$

The values of the probability function $f(\chi ; \beta, \gamma)$ can be estimated from the observed variables (yield strength, compression strength, the surface roughness of scan and built plane) arranged in an increasing order using the following equation;

$$
f\left(x_{i} ; \beta, \gamma\right)=\left(x_{i}-0.5\right) / n,
$$

Where $\mathrm{n}=20$ is the sample size of the experiment and $\chi_{\mathrm{i}}$ is the value of the variable at $\mathrm{i}^{\text {th }}$ rank. The values $\mathrm{Y}=\ln \left[\ln \left(\frac{1}{1-f(x ; \beta, \gamma)}\right)\right]$ and $X=\ln (\chi)$ are plotted for linear regression to estimate the parameters $\beta$ and $\gamma$, as shown in Figure 2. Table 2 shows the corresponding values of parameters $\beta$ and $\gamma$ for different variables evaluated in this experiment. The shape parameter $\gamma>0$, signifies an increase in failure rate with an increase in the measured variable. Larger $\gamma$ shows the higher probability of a material failure for every unit increase in compression values. On the other hand, parameter $\beta$ signifies the distribution scale of the measured data, as shown in Table 2.

\section{RESULTS AND DISCUSSION}

As observed in Table 1, the SLS-built PA2200 polyamide samples exhibit different compressive strength and surface roughness values. The compressive yield strength and the maximum compressive strength were found to vary in between 22-34 MPa and 59-70 MPa, respectively, which agrees well with previous results $[1,14,15]$. The difference of nearly $10-12 \mathrm{MPa}$ in the compressive 


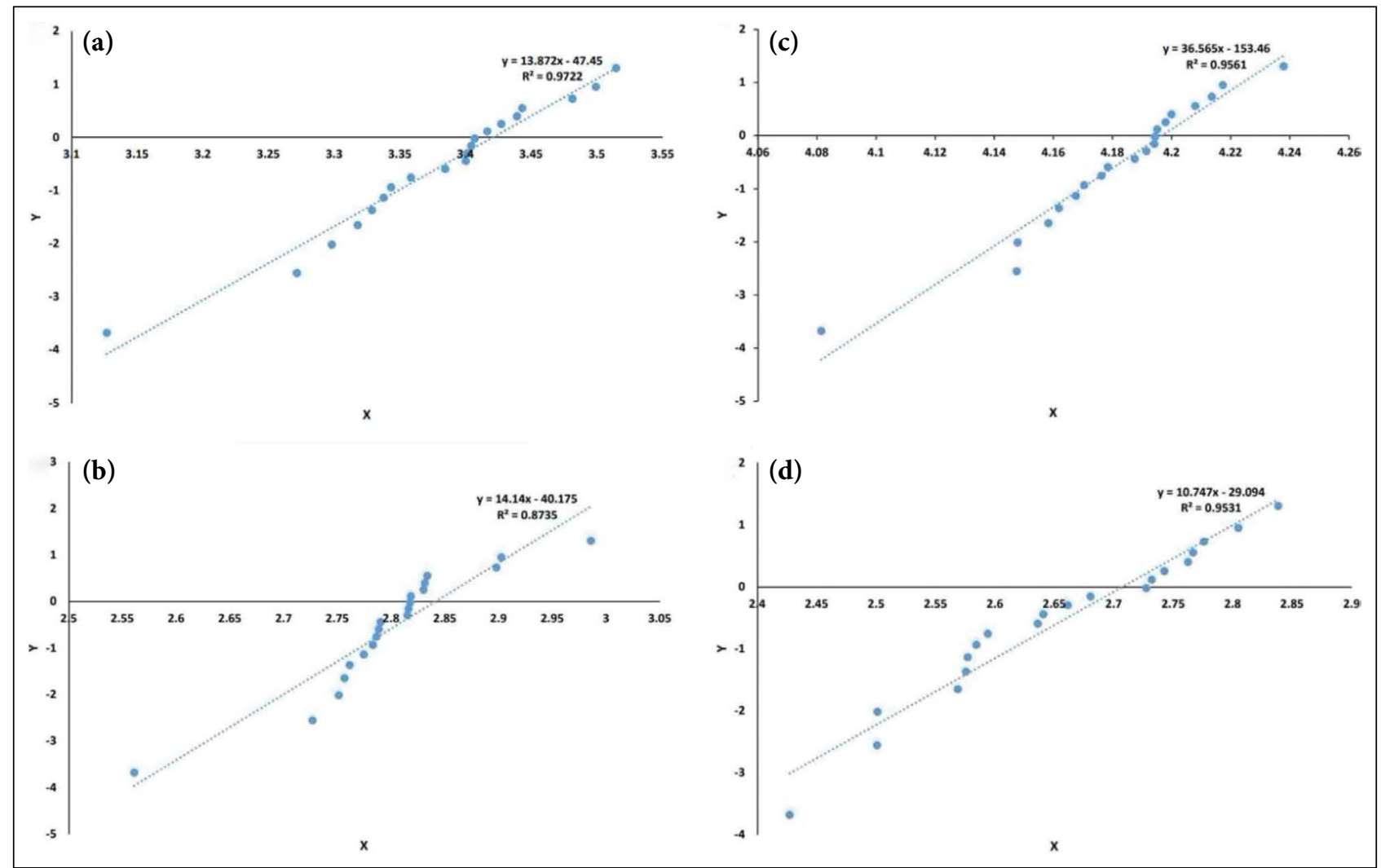

Figure 2. The regression line for (a) compressive yield stress, (b) compressive strength, and surface roughness of the (c) scan plane, and (d) built plane.

Table 2. The shape $\beta$ and scale parameters $\gamma$ and the corresponding linearized Weibull plot

\begin{tabular}{lccc}
\hline Variable & Shape parameter, $\boldsymbol{\beta}$ & Scale parameter, $\boldsymbol{\gamma}$ & Straight line equation \\
\hline Yield strength & 30.59 & 13.87 & $\mathrm{Y}=13.87 \mathrm{X}-47.45$ \\
Compressive strength & 66.47 & 36.57 & $\mathrm{Y}=36.57 \mathrm{X}-153.46$ \\
Roughness, scan plane & 17.14 & 14.14 & $\mathrm{Y}=14.14 \mathrm{X}-17.14$ \\
Roughness, built plane & 14.99 & 10.75 & $\mathrm{Y}=10.75 \mathrm{X}-29.09$ \\
\hline
\end{tabular}

strength is quite significant and it can be attributed to the change in densification between the sintered samples. The SLS components are known for their high internal porosity and that can vary depending mainly on the packing density of the sintered layers.

The surface roughness of the two planes was also found to differ by an average of $7 \mu \mathrm{m}$ in the observed samples. The surface roughness of the SLS components is relatively high compared to the samples prepared by the conventional methods, and this is due to the characteristic behavior of the sintering process where powder particles are fused together through a neck formation [16, 17]. Moreover, the surface roughness of the built plane was found lower than the scan plane, which is contrary to the surface roughness behavior of the metals produced from the selective laser melting (SLM) process [18]. The amount of incident energy in the SLS process is relatively lower than the SLM process that results in a lesser extent of powder sticking to the edges of the SLS components [1]. The surface roughness variation between the two planes was found in the range of $0.4-5.4 \mu \mathrm{m}$ with an average surface roughness variation of about $2.5 \mu \mathrm{m}$.

Figure 3 shows the reliability graph of the four variables, and Table 3 shows the reliability values of the occurrence of the respective variables at $90 \%$. For example, the Weibull analysis shows that the polyamide samples produced by the SLS process are expected to have at least $62.63 \mathrm{MPa}$ of maximum compressive strength.

\section{CONCLUSION}

The physical and mechanical properties of the SLS components are not static as it varies with samples even fabricated at the same time and at the same fabricating conditions. 
Table 3. Reliability distributions corresponding to various stress values for both compressive yield stress and compressive strength

\begin{tabular}{lcccc}
\hline Parameters & $\begin{array}{c}\text { Yield strength } \\
(\mathbf{M P a})\end{array}$ & $\begin{array}{c}\text { Compressive strength } \\
(\mathbf{M P a})\end{array}$ & $\begin{array}{c}\text { Scan plane, } \mathbf{R}_{\mathrm{a}} \\
(\boldsymbol{\mu} \mathrm{m})\end{array}$ & $\begin{array}{c}\text { Built plane, } \mathbf{R}_{\mathrm{a}} \\
(\boldsymbol{\mu} \mathrm{m})\end{array}$ \\
\hline $\mathrm{R}(90 \%)$ & 26.07 & 62.63 & 14.81 & 12.15 \\
\hline
\end{tabular}
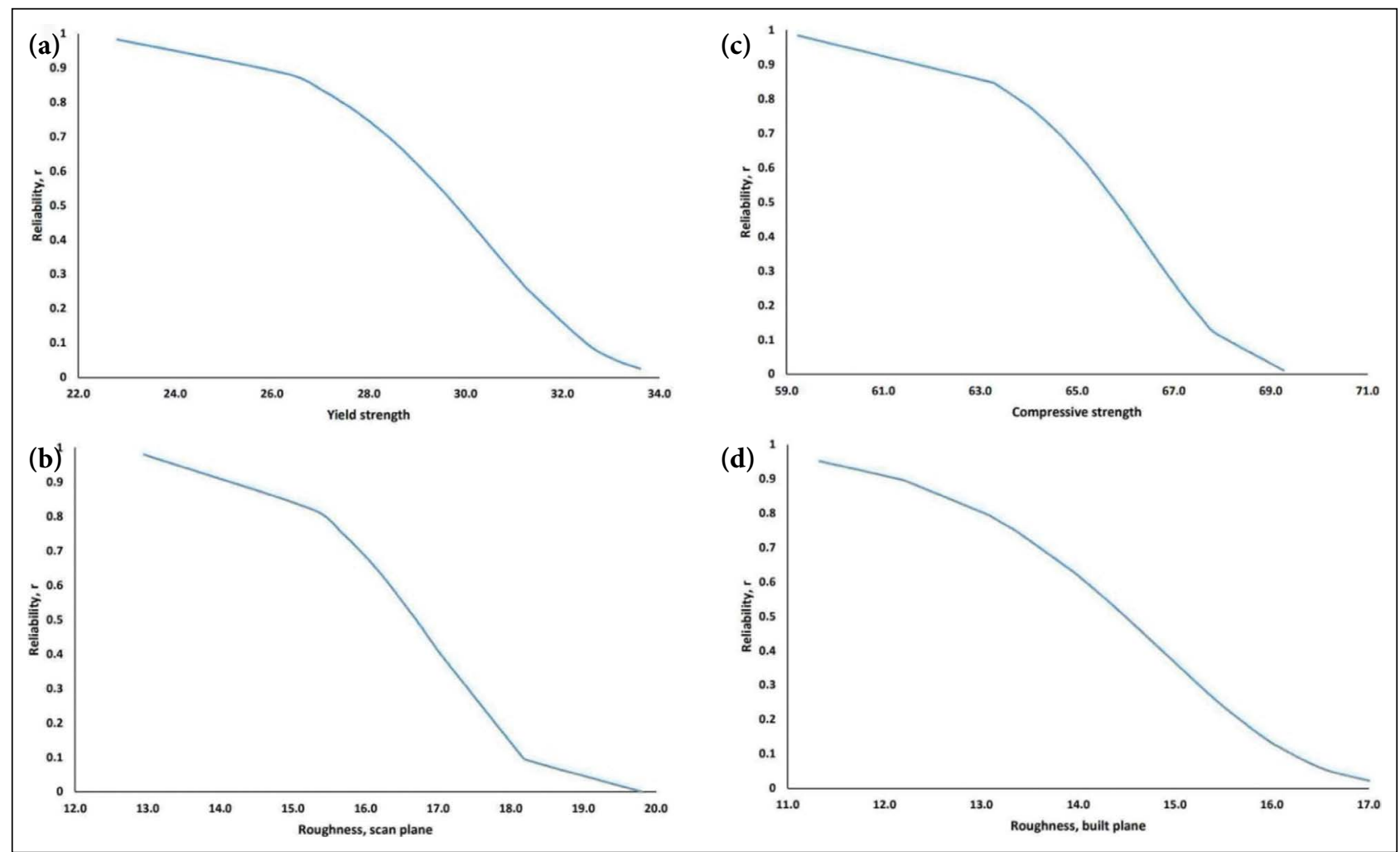

Figure 3. Reliability distribution for (a) yield strength, (b) compressive strength, and surface roughness of the (c) scan and the (d) built plane.

Weibull distribution analysis was carried out on the as-built SLS polyamide PA2200 samples to evaluate the distribution in properties such as compressive yield strength, maximum compressive strength, and surface roughness of the two orthogonal planes, parallel and perpendicular to the scanning direction. The study clearly establishes a significant variance in the values of the measured variables. The difference in the values of the compressive strength and surface roughness of the two planes was found approximately in the range of 10-12 $\mathrm{MPa}$ and 6-7 $\mu \mathrm{m}$, respectively.

The surface roughness of the built side was found lower than the surface roughness of the scan side of the as-built SLS PA2200 samples. In the present case, the compressive yield strength, maximum compressive strength, surface roughness of the scan, and the built plane with $90 \%$ reliability were found to be $26.07 \mathrm{MPa}, 62.63 \mathrm{MPa}, 14.81 \mu \mathrm{m}$, and $12.15 \mu \mathrm{m}$, respectively.

\section{Data Availability Statement}

The published publication includes all graphics and data collected or developed during the study.

\section{Author's Contributions}

Hamaid Mahmood Khan: Conceived the investigation, oversaw the course of the experiment, and developed and authored the text.

Gürkan Tarakçı: Carried out tests and participated in the procurement of materials. Assisted the experiment's progress.

Mustafa Enes Bulduk: Carried out tests and participated in the procurement of materials. Assisted the experiment's progress.

Ebubekir Koç: Drafted, supervised, and assisted in writing the manuscript.

\section{Conflict of interest}

The authors declared no potential conflicts of interest with respect to the research, authorship, and/or publication of this article.

\section{Ethics}

There are no ethical issues with the publication of this manuscript. 


\section{REFERENCES}

[1] Khan, H. M., Sirin, T. B., Tarakci, G., Bulduk, M. E., Coskun, M., Koc, E., \& Kaynak, Y. (2021). Improving the surface quality and mechanical properties of selective laser sintered PA2200 components by the vibratory surface finishing process. SN Applied Sciences, 3, 364, 1-14.

[2] Khan, H. M., Dirikolu, M. H., \& Koç, E. (2018). Parameters optimization for horizontally built circular profiles: Numerical and experimental investigation. Optik, 174, 521-529.

[3] Zarringhalam, H., Hopkinson, N., Kamperman, N. F., \& de Vlieger, J. J. (2006). Effects of processing on microstructure and properties of SLS Nylon 12. Materials Science and Engineering A, 435-436, 172-180.

[4] Schmidt, J., Sachs, M., Blümel, C., Winzer, B., Toni, F., Wirth, K. E., \& Peukert, W. (2015). A novel process chain for the production of spherical sls polymer powders with good flowability. Procedia Engineering, 102, 550-556.

[5] Khan, H. M., Karabulut, Y., Kitay, O., Kaynak, Y., Jawahir, I. S., Mahmood, K. H. (2021). Influence of the post-processing operations on surface integrity of metal components produced by laser powder bed fusion additive manufacturing: a review. Machining Science and Technology, 25(1), 118-176.

[6] Zhou, J., Zhang, Y., \& Chen, J. K. (2009). Numerical Simulation of Random Packing of Spherical Particles for Powder-Based Additive Manufacturing. Journal of Manufacturing Science and Engineering, 131(3), 031004.

[7] Salmoria, G. V, Leite, J. L., Ahrens, C. H., Lago, A., \& Pires, A. T. N. (2007). Rapid manufacturing of PA/ HDPE blend specimens by selective laser sintering: Microstructural characterization. Polymer Testing, 26(3), 361-368.

[8] Özbay, B., \& Serhatll, E. (2020). Processing and Characterization of Hollow Glass-Filled Polyamide 12 Composites by Selective Laser Sintering Method. Materials Technology, 00(00), 1-11.

[9] Koç, E., Çalışkan, C. İ., Coşkun, M., \& Khan, H. M.
(2020). Unmanned Aerial Vehicle Production With Additive Manufacturing. Journal of Aviation, 4(1), 22-30.

[10] Keleş, Ö., Blevins, C. W., \& Bowman, K. J. (2017). Effect of build orientation on the mechanical reliability of 3D printed ABS. Rapid Prototyping Journal, 23(2), 320-328.

[11] Dirikolu, M. M. H., Aktas, A., \& Birgoren, B. (2002). Statistical analysis of fracture strength of composite materials using Weibull distribution. Turkish Journal of Engineering and Environmental Sciences, 26(1), 45-48.

[12] Khan, H. M., Dirikolu, M. H., \& Koç, E. (2019). Weibull distribution of selective laser melted AlSi10Mg parts for compression testing. AMC Turkey 2019 Conference, İstanbul, 1, 1-9.

[13] Weibull, W. (1951). A statistical distribution function of wide applicability. Journal of Applied Mechanics, 18, 290-293.

[14] Borzan, C. S. M., Moldovan, M., \& Bocanet, V. (2018). Evaluation of Surface Modification of PA 2200 Parts Made by Selective Laser Sintering Process. Revista de Chimie, 69(4), 886-889.

[15] Liu, S., Xi, Z., Tang, H., Yang, X., Zhang, Z., \& Liu, Q. (2014). Sintering Behavior of Porous Titanium Fiber Materials. Journal of Iron and Steel Research, International, 21(9), 849-854.

[16] Drummer, D., Rietzel, D., \& Kühnlein, F. (2010). Development of a characterization approach for the sintering behavior of new thermoplastics for selective laser sintering. Physics Procedia, 5(2), 533-542.

[17] Sing, S. L., Wiria, F. E., \& Yeong, W. Y. (2018). Selective laser melting of titanium alloy with $50 \mathrm{wt} \%$ tantalum: Effect of laser process parameters on part quality. International Journal of Refractory Metals and Hard Materials, 77, 120-127.

[18] Khan, H. M., Özer, G., Tarakci, G., Coskun, M., Koc, E., \& Kaynak, Y. (2021). The impact of aging and drag-finishing on the surface integrity and corrosion behavior of the selective laser melted maraging steel samples. Materialwissenschaft und Werkstofftechnik, 52(1), 60-73. 